\title{
CORTINARIUS ALPINUS AS AN EXAMPLE FOR MORPHOLOGICAL AND PHYLOGENETIC SPECIES CONCEPTS IN ECTOMYCORRHIZAL FUNGI
}

\section{U. Peintner}

Peintner, U. 2008. Cortinarius alpinus as an example for morphological and phylogenetic species concepts in ectomycorrhizal fungi. - Sommerfeltia 31: 161-177. ISBN 82-7420-045-4. ISSN 08006865 .

Extensive morphological and molecular analyses of closely related species from alpine, subalpine and montane habitats should enable a comparison of ecological, morphological and phylogenetic species concepts in ectomycorrhizal mushrooms. One fundamental question of this study was whether alpine species really exist, and which criteria, besides the specific habitat, could reliably be used for the delimitation of such taxa. For this reason, 56 rDNA ITS sequences were generated or downloaded from GenBank for 10 closely related species of Cortinarius subgenus Myxacium, section Myxacium. Several collections were sequenced for each of the following taxa: Cortinarius absarokensis, C. alpinus, $C$. favrei, C. fennoscandicus, C. grallipes, C. mucosus, C. muscigenus, C. septentrionalis, $C$. trivialis and C. vernicosus. Moreover, spore statistics were carried out for 38 collections of alpine and subalpine taxa. These data provide clear evidence for $C$. favrei being a synonym of $C$. alpinus. C. absarokensis and $C$. alpinus can clearly be delimited based on pileus diameter and average dry weight per basidiome, even in overlapping habitats, but spore size and shape is not a good distinguishing character. Phylograms have very short branches, and base differences between ITS sequences are generally very low in this group, and give no resolution for the included taxa of this section. Based on these results, species concepts of ectomycorrhizal mushrooms are discussed in detail.

Keywords: Cortinarius, host specificity, morphological species recognition, phylogenetic species recognition.

Ursula Peintner, Institute of Microbiology, Leopold-Franzens-University Innsbruck, Technikerstr. 25,6020Innsbruck, Austria.ursula.peintner@uibk.ac.at

\section{INTRODUCTION}

Cortinarius favrei M.M. Moser ex Henderson is one of the most frequently reported alpine Cortinarius spp. associated with dwarf willows (e.g. Salix herbacea, S. polaris) and Dryas (e.g. Watling 1977, 1987, Schmid-Heckel 1985, Kühner \& Lamoure 1986, Senn-Irlet 1987, Peintner et al. 1999, Jamoni \& Bon 1993, Moser 1993, Nezdoiminogo 1993, 2002). Cortinarius alpinus Boud. was reported as a second alpine Myxacium differing from C. favrei by larger spores (Trimbach 1978). The 
morphologically very similar Cortinarius absarokensis M.M. Moser \& McKnight was described from subalpine to arctic/alpine habitats with shrubby willows vegetation. This taxon differs by much larger basidiomes from C. favrei.

Moreover, a considerable number of morphologically closely related taxa have been described from other habitats: C. fennoscandicus E. Bendiksen, K. Bendiksen \& Brandrud, C. grallipes Fr., C. mucosus (Bull.) Kickx, C. muscigenus Peck [=C. cylindripes Kauffm., C. collinitus (Sow.: Fr.) Fr. sensu J. Lange], C. septentrionalis E. Bendiksen, K. Bendiksen \& Brandrud, C. trivialis J.E. Lange $[=C$. collinitus (Sow.: Fr.) Fr.] and C. vernicosus M.T. Seidl occur all in boreal habitats in association with mostly deciduous trees. The nomenclature of these boreal taxa follows Bendiksen et al. (1993).

Ecological, morphological and phylogenetic species concepts in ectomycorrhizal mushrooms can be tested based on analyses of closely related species from alpine, subalpine and montane habitats. Morphological species concepts of boreal to upper boreal taxa occurring in Fennoscandia were extensively studied by Bendiksen et al. (1993). The aim of the present study is to focus on alpine taxa of this species complex, and to test the morphological and ecological species concepts of Bendiksen et al. (1993) with molecular tools.

\section{MATERIAL AND METHODS}

\section{Material}

The collections used in this study are listed in Table 1 together with additional information.

\section{Morphometric studies}

Morphometric studies were carried out on a total of 51 collections from Europe, Siberia and North America. Spore measurements focussed on C. alpinus (including the synonym C. favrei) (30 coll.), C. absarokensis (8 collections including the typus material), and C. trivialis (7 coll.). As extensive spore measurements have already been carried out by Bendiksen et al. (1993), a maximum of three collections were measured in this study for five non-alpine, additional taxa of the section Myxacium (C. fennoscandicus, C. grallipes, C. mucosus, C. muscigenus, C. septentrionalis). In order to measure mature spores, spores were taken from spores deposited on the cortina or stipe. All specimens were examined by means of standard microscopic techniques: microscopy was carried out with a Nikon Eclipse E600, data were documented by video prints produced with a Sony video camera SASCC350P and a Sony video printer UP 910. Spores were mounted in $3 \% \mathrm{KOH}$ and measured on prints at magnification $1400 \times$. For statistical evaluation of spore size, 31 spores were measured per collection. Thus, a total of 1581 spores were measured for this study. Data are provided in the form (min) mean $\pm \mathrm{sd}(\max ) \times(\min )$ mean $\pm \mathrm{sd}(\max )$.

Basidiome data (pileus diameter and average dry weight per basidiome) were measured from 50 herbarium collections, as for several collections only pileus fragments were available. The pileus diameter of all basidiomes with open pilei was measured for each collection. All measured, not fragmented basidiomes were then weighted together, and the average dry weight per basidiome was calculated.

Six quantitative characters were evaluated and statistically analysed: spore length (L), spore width $(\mathrm{W})$, spore quotient $(\mathrm{Q}=\mathrm{L} / \mathrm{W})$, spore volume $(\mathrm{V})$, pileus diameter and average dry weight / ba- 
sidiome. Standard parametric statistical methods (Quinn \& Keough 2002) were used: $t$-tests, univariate analysis of variance (ANOVA), multivariate analysis of variance (MANOVA) and Discriminant Analysis were carried out with the program BMDP, Version 7 (Statistical Software Inc., Version 7 , University of Los Angeles). Graphics were made with SPSS, Version 12 (SPSS, Chicago, Illinois).

\section{Molecular methods}

Sequences of the rDNA internal transcribed spacer (ITS) were usually generated for the same collections as used for the morphological investigation. Moreover, two collections of C. livido-ochraceus were generated for reasons of comparison; ten sequences for the in- and outgroup (Cortinarius subgenus Myxacium section Defibulati) were retrieved from Genbank. Thus, all together 56 rDNA ITS sequences were used for the phylogenetic analysis of the species complex around C. alpinus: 22 collections of $C$. alpinus (collections originally named $C$. favrei) from a wide geographical and morphological range (Europe, Greenland, Russian Far East, USA), ten sequences of C. absarokensis, ten of $C$. trivialis, three of C. mucosus and two sequences each of $C$. fennoscandicus, C. septentrionalis, C. muscigenus, C. pingue and one sequence of $C$. vernicosus. DNA isolation, PCR amplification and sequencing were carried out as previously described (Peintner et al. 2002, Thomas et al. 2002). Sequences are deposited in GenBank under the Accession Numbers DQ295083-DQ295122. Nucleotide sequences were aligned manually in the data editor of PAUP* 4b10 (Swofford 2003).

Maximum parsimony (MP) and Maximum likelihood (ML) phylogenetic searches were carried out using PAUP*4.0b10. Maximum parsimony analyses (MP) with heuristic searches were performed with the following settings: MULPARS = on, steepest descent not in effect, MAXTREES 10000, transitions twice the weight of transversions, gaps treated as missing data. The most parsimonious trees (MPT) were searched with tree-bisection-reconnection (TBR) branch swapping. Starting trees were obtained by random sequence addition; 100 heuristic searches were performed and no more than 10 trees of score (length) greater than or equal to one were saved in each replicate. The resulting shortest trees were used as starting trees for a more extensive search with a TBR reconnection limit of 10. Relative robustness for individual branches was estimated by bootstrap, using 500 replicates, with heuristic searches, 10 random addition sequences, TBR and MAXTREES set to 10000. The program Modeltest version 3.06 (Posada \& Crandall 1998) was used to test the model of DNA substitution. Maximum likelihood (ML) analysis was carried out with starting branch lengths obtained using Rogers-Swofford approximation method and employing the likelihood settings from the best-fit model selected by Modeltest. Bootstrap support for branches obtained in ML searches was estimated by 500 replicates of the "fast bootstrap" option in PAUP* using the same likelihood settings.

\section{RESULTS}

\section{Morphometric analyses}

\section{Basidiospores}

Species of section Myxacium had a very uniform micro morphology: Spore sizes did not differ significantly between the different species, due to high standard deviations and overlapping data (Tab. 2, Figs. 1-2). Spore length variation was highest for C. alpinus, C. trivialis and C. fennoscandicus. 
Tab. 1. Collections used on this study with information on locality, ecology, voucher number, Genbank accession numbers, and spore statistics (SS) as well as statistics of macrodata (MD = pileus diameter and dry weight).

\begin{tabular}{|c|c|c|c|c|c|c|}
\hline Taxon & Locality & Ecology & VoucherNr. & GB AccNo & SS & MD \\
\hline C. absarokensis & France & S. foetida & IB19920119 & DQ295098 & + & + \\
\hline C. absarokensis & Greenland & S. glauca & IB20000033 & DQ295099 & + & + \\
\hline C. absarokensis & USA, Col. & alpine & ZTUSA7492 & DQ295101 & + & \\
\hline C. absarokensis & USA, Col. & alpine & ZT9533 & DQ295094 & + & \\
\hline C. absarokensis & USA, Col. & alpine & ZT9726 & DQ295092 & + & \\
\hline C. absarokensis & USA, Col. & alpine & ZT9727 & DQ295093 & + & \\
\hline C. absarokensis & USA, Col. & alpine & ZTUSA7489 & DQ295102 & + & \\
\hline C. absarokensis & USA, Col. & alpine & ZTCa07 & DQ295096 & & \\
\hline C. absarokensis & USA, Wash. & Salix sp. & IB19890343 & & & + \\
\hline C. absarokensis & USA, Wyo. & S. arctica & IB19870294 & DQ295097 & & + \\
\hline C. absarokensis & USA, Wyo. & S. glauca & IB19890309 & & & + \\
\hline C. absarokensis & USA, Wyo. & S. phylicifolia & IB19910302 & & & + \\
\hline C. absarokensis & USA, Wyo. & S. phylicifolia & IB19910303 & & & + \\
\hline C. absarokensis & USA, Wyo. & S. phylicifolia & IB19910376 & & & + \\
\hline C. absarokensis Typus & USA, Mon. & S. arctica & IB19830352 & DQ295100 & + & + \\
\hline C. alpinus & France & S. herbacea & Trimbach 2217 & + & + & \\
\hline C. alpinus & France & S. herbacea & Trimbach 1457 & + & + & \\
\hline C. alpinus & France & S. herbacea & Trimbach2449 & + & + & \\
\hline C. alpinus & Switzerland & S. retusa & Trimbach1105 & DQ295083 & + & + \\
\hline C. alpinus & Austria & alpine & IB19590013 & & + & + \\
\hline C. alpinus & Austria & S. retusa & IB19950703 & & + & + \\
\hline C. alpinus & France & S. herbacea & Trimbach 1473 & + & + & \\
\hline C. alpinus & France & S. herbacea & IB19920151 & & + & + \\
\hline C. alpinus & Greenland & S. herbacea & IB20000066 & DQ295081 & + & + \\
\hline C. alpinus & Italy, Abruzzo & S. retusa & Pacioni/gr & DQ295084 & + & + \\
\hline C. alpinus & Italy, Abruzzo & S. retusa & Pacioni/kl & & + & + \\
\hline C. alpinus & Norway & S. herbacea & IB19840090 & DQ295078 & + & + \\
\hline C. alpinus & Russia & alpine & IB19990627 & AF325575, DQ295087 & + & + \\
\hline C. alpinus & Spitzbergen & S. polaris & IB19880124 & & + & + \\
\hline C. alpinus & USA, Alaska & S. rotundifolia & IB19800187 & DQ295082 & + & + \\
\hline C. alpinus & USA, Col. & alpine & ZTUSA2IS 10 & DQ295089 & & \\
\hline C. alpinus & USA, Col. & alpine & ZTUSA8092 & DQ295091 & & \\
\hline C. alpinus & USA, Col. & S. reticulata & ZTUSA39E & DQ295086 & & \\
\hline C. alpinus & USA, Col. & S. reticulata & HorakC.f.07 & DQ295085 & & \\
\hline C. alpinus & USA, Wyo. & S. arctica & IB19910312 & & + & + \\
\hline C. alpinus fm. pallidus & Spitzbergen & S. polaris & IB19880054 & DQ295079 & + & + \\
\hline C. alp. fm. pallidus & USA, Wyo. & S. arctica & IB19910286 & DQ295072 & + & + \\
\hline C. alp. fm. pallidus & USA, Wyo. & Salix sp. & IB19830338b & + & + & \\
\hline C. alp. fm. pallidus Typus & USA, Wyo. & alpine & IB19830338 & DQ295071 & & \\
\hline C. alp. var. microsporus & Switzerland & S. reticulata & IB19840181b & + & + & \\
\hline C. alp. var. microsporus & USA, Wyo. & S. arctica & IB19910314 & DQ295080 & & \\
\hline C. alp. var. microsporus & USA, Wyo. & S. arctica & IB19910293 & DQ295073 & + & + \\
\hline C. alp. viol. lamellae & Austria & S. herbacea & IB19660136 & DQ295075 & + & + \\
\hline C. alp. viol. lamellae & Austria & S. herbacea & IB19670047 & DQ295074 & + & + \\
\hline C. alp. viol. lamellae & Austria & S. retusa & IB19950101 & DQ295076 & + & + \\
\hline C. alp. viol. lamellae & USA, Col. & alpine & ZTUSA8160 & DQ295090 & + & \\
\hline C. alp. viol. lamellae & USA, Col. & alpine & ZTUSA115HV14 & DQ295088 & & \\
\hline C. alp. viol. lamellae & USA, Col. & alpine & ZT9765 & DQ295077 & + & \\
\hline C. fennoscandicus & Finland & B. tortuosa & IB1970135a & DQ295105 & + & + \\
\hline C. fennoscandicus & Finland & Betula tortuosa & IB19980039 & DQ295106 & & + \\
\hline C. grallipes & Russia & B. rotundifolia & IB20010104 & & + & + \\
\hline C. grallipes & Sweden & B. tortuosa & IB19840051 & & + & + \\
\hline
\end{tabular}


Tab. 1 (cont.). Collections used on this study with information on locality, ecology, voucher number, Genbank accession numbers, and spore statistics (SS) as well as statistics of macrodata (MD = pileus diameter and dry weight).

\begin{tabular}{|c|c|c|c|c|c|c|}
\hline Taxon & Locality & Ecology & VoucherNr. & GB AccNo & SS & MD \\
\hline C. grallipes & Sweden & B. tortuosa & IB19910286 & & + & \\
\hline C. livido-ochraceus & Italy & deciduous trees & A2001110902 & & & \\
\hline C. livido-ochraceus & Italy & deciduous trees & A2001110902 & DQ295121 & & \\
\hline C. livido-ochraceus & Italy & Quercus cerris & IB19960258 & & & \\
\hline C. livido-ochraceus & Italy & Quercus cerris & IB19960258 & DQ295122 & & \\
\hline C. mucosus & Russia & Pinus sibirica & IB20010101 & DQ295115 & & \\
\hline C. mucosus & USA, Cal. & Pinus muricata & IB19910694 & DQ295114 & + & + \\
\hline C. muscigenus & Austria & Picea & IB19960061 & DQ295118 & & \\
\hline C. muscigenus & Sweden & Picea & IB19940257 & DQ295117 & & \\
\hline C. muscigenus & USA, Cal. & Picea, Abies & IB19890443 & DQ295116 & & \\
\hline C. pingue & USA, Ore, & Abies & IB19760501 & DQ295119 & & \\
\hline C. pingue & USA, Ore, & Picea, Pinus & IB19951102 & DQ295120 & & \\
\hline C. septentrionalis & Greenland & B. nana & IB20000048 & DQ295103 & + & + \\
\hline C. septentrionalis & Norway & B. tortuosa & IB19950027 & & + & + \\
\hline C. septentrionalis & Norway & B. tortuosa & IB19840141 & DQ295104 & & + \\
\hline
\end{tabular}

C. fennoscandicus showed a trend to having the longest median spore values $(13 \mu \mathrm{m})$, while the shortest median spores occurred in C. trivialis $(11.5 \mu \mathrm{m})$. Also spore width variation was comparatively high: $C$. grallipes, $C$. mucosus, and $C$. trivialis were characterized by narrow spores (median $<7 \mu \mathrm{m}$ ), while spore width of $C$. absarokensis, and C. alpinus usually exceeded a median value of $7 \mu \mathrm{m}$. C. fennoscandicus spores width was in median $7 \mu \mathrm{m}$. Thus, C. absarokensis, C. alpinus and C. grallipes had nearly identical mean spore quotients. Trends towards higher spore quotients could clearly be observed for $C$. mucosus (due to narrow spores). C. septentrionalis spores showed a trend towards lower spore quotients. Within collections of $C$. alpinus, no significant differences could be found between the unpublished small-spored variety and the other collections.

Tab. 2. Mean values (MW), standard deviation (SD), minima (MIN) and maxima (MAX) for all spores from all collections studied for one taxon.

\begin{tabular}{|c|c|c|c|c|c|c|c|c|c|c|c|c|c|}
\hline \multirow[t]{2}{*}{ Taxon } & \multirow[t]{2}{*}{ spores } & \multicolumn{4}{|l|}{ Q } & \multicolumn{4}{|l|}{$\mathrm{L}$} & \multicolumn{4}{|l|}{$\mathrm{W}$} \\
\hline & & MW & SD & MIN & MAX & MW & SD & MIN & MAX & MW & SD & MIN & MAX \\
\hline C. absarokensis & $\mathrm{n}=31$, Typus & 1.8 & 0.1 & 1.6 & 1.9 & 13.6 & 0.8 & 12.1 & 15.4 & 7.7 & 0.4 & 7.8 & 8.8 \\
\hline C. absarokensis & $\mathrm{n}=154,5$ coll & 1.7 & 0.1 & 1.3 & 2.1 & 12.3 & 0.8 & 9.8 & 15.4 & 7.4 & 0.6 & 6.3 & 8.8 \\
\hline C. alpinus & $\mathrm{n}=929,30$ coll. & 1.7 & 0.2 & 1.4 & 2.5 & 12.7 & 1.2 & 9.8 & 17.5 & 7.4 & 0.7 & 5.6 & 12.6 \\
\hline C. favrei f. pallidus & $\mathrm{n}=31$, Typus & 1.7 & 0.1 & 1.5 & 2.0 & 12.7 & 1.0 & 11.2 & 15.1 & 7.6 & 0.4 & 5.6 & 8.4 \\
\hline C. favrei / microsporus & $\mathrm{n}=31,1$ coll. & 1.6 & 0.1 & 1.3 & 1.9 & 11.9 & 1.0 & 9.8 & 13.3 & 7.5 & 0.6 & 6.3 & 8.8 \\
\hline C. grallipes & $\mathrm{n}=93,3$ coll. & 1.7 & 0.1 & 1.3 & 2.1 & 12.2 & 0.8 & 10.5 & 14.0 & 7.1 & 0.5 & 6.3 & 8.4 \\
\hline C. mucosus & $\mathrm{n}=31,1$ coll. & 1.8 & 0.1 & 1.5 & 2.1 & 12.5 & 0.6 & 11.2 & 13.7 & 6.8 & 0.6 & 5.6 & 8.1 \\
\hline C. septentrionalis & $\mathrm{n}=62,2$ coll. & 1.6 & 0.2 & 1.3 & 2.1 & 11.9 & 0.5 & 9.8 & 13.3 & 7.4 & 0.6 & 5.6 & 9.1 \\
\hline C. trivialis & $\mathrm{n}=248,8$ coll & 1.7 & 0.2 & 1.4 & 2.3 & 11.7 & 1.3 & 9.1 & 16.1 & 6.8 & 0.5 & 5.6 & 8.4 \\
\hline
\end{tabular}



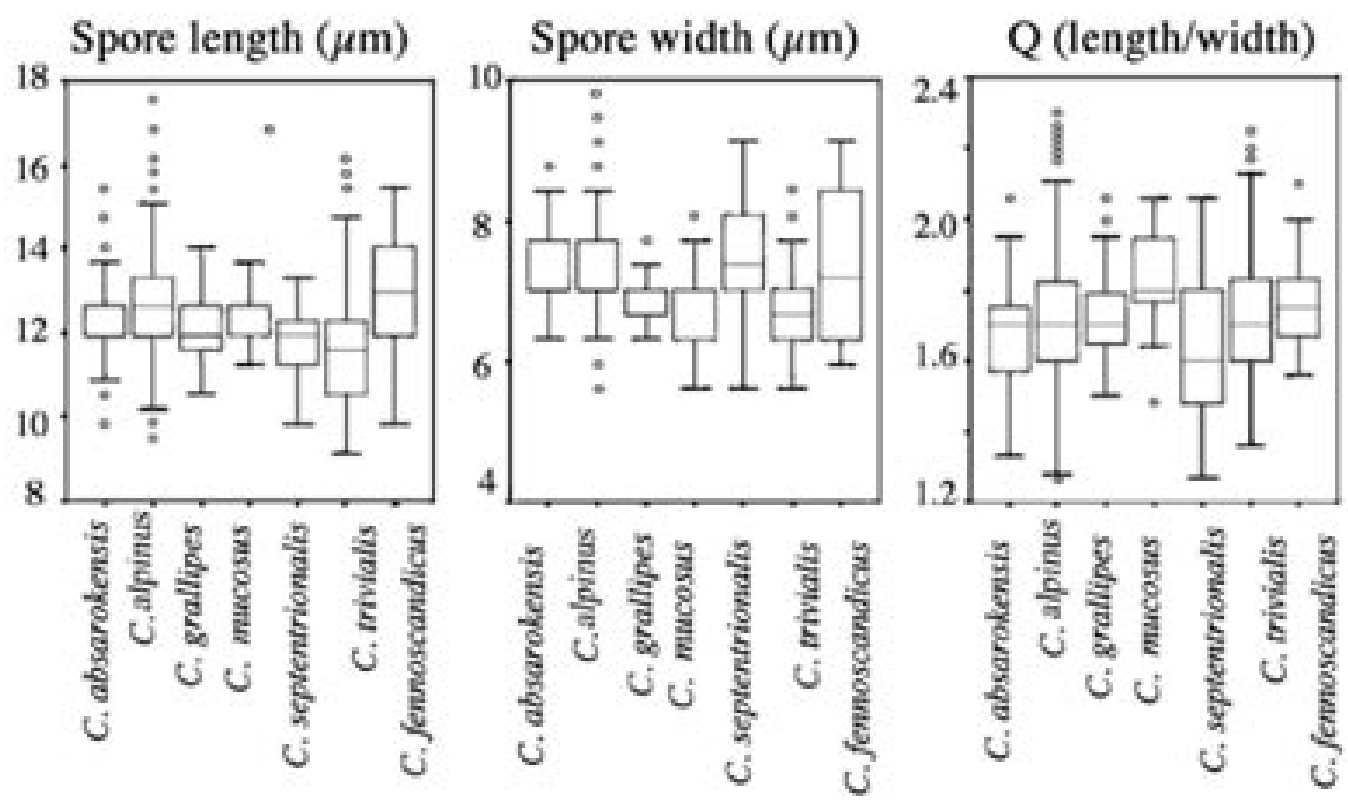

Fig. 1. Box plots for spore length, width and Q of seven species of Cortinarius subgenus Myxacium, section Myxacium: C. absarokensis (number of collections studied/number of spores measured = 3/155), C. alpinus (32/992), C. grallipes (2/62), C. mucosus (1/31), C. septentrionalis (2/62), C. trivialis $(7 / 217), C$. fennoscandicus (2/62). Boxes represent the median, the upper and lower quartiles, and the extreme values; outliers are shown as dots.

Basidiome data

Basidiome data varied considerably between species (Fig. 3): C. absarokensis ( $\mathrm{n}=10$ coll.) had basidiomes with a pileus diameter of (34) $53 \pm 11$ (70) $\mathrm{mm}$, and a dry weight of (1.2) $2.5 \pm 0.9$ (3.9) $\mathrm{g}$ /basidiome. C. alpinus ( $\mathrm{n}=25$ coll.) was characterized by basidiomes with a pileus diameter of (11) $23 \pm 10$ (49) $\mathrm{mm}$, and a dry weight of (0.1) $0.6 \pm 0.7$ (2.7) g/basidiome. These two alpine species represented extreme values in the species complex of section Myxacium, C. absarokensis with the highest pileus diameter and dry average weight per basidiome, and C. alpinus with the lowest values. The other taxa did not differ considerably from each other (C. fennoscandicus: pileus diameter of (36) $40 \pm 3$ (43) mm, and a dry weight of (0.9) $1.3 \pm 0.4$ (1.7) g/basidiome ( $\mathrm{n}=3)$; C. trivialis: pileus diameter of (30) $40 \pm 10$ (55) $\mathrm{mm}$, and a dry weight of (0.3) $1.5 \pm 1.2(3.3) \mathrm{g} /$ basidiome $(\mathrm{n}=7)$.

\section{Phylogenetic analyses}

The alignment of ITS data included 61 sequences. After the introduction of gaps to optimise homology in the sequence alignment, the alignment was 849 nucleotide positions long. Areas of ambiguous alignment were excluded from the analysis, resulting in 286 excluded and 553 included characters. 432 characters were constant, 50 were parsimony-uninformative and 71 characters were parsimonyinformative. 

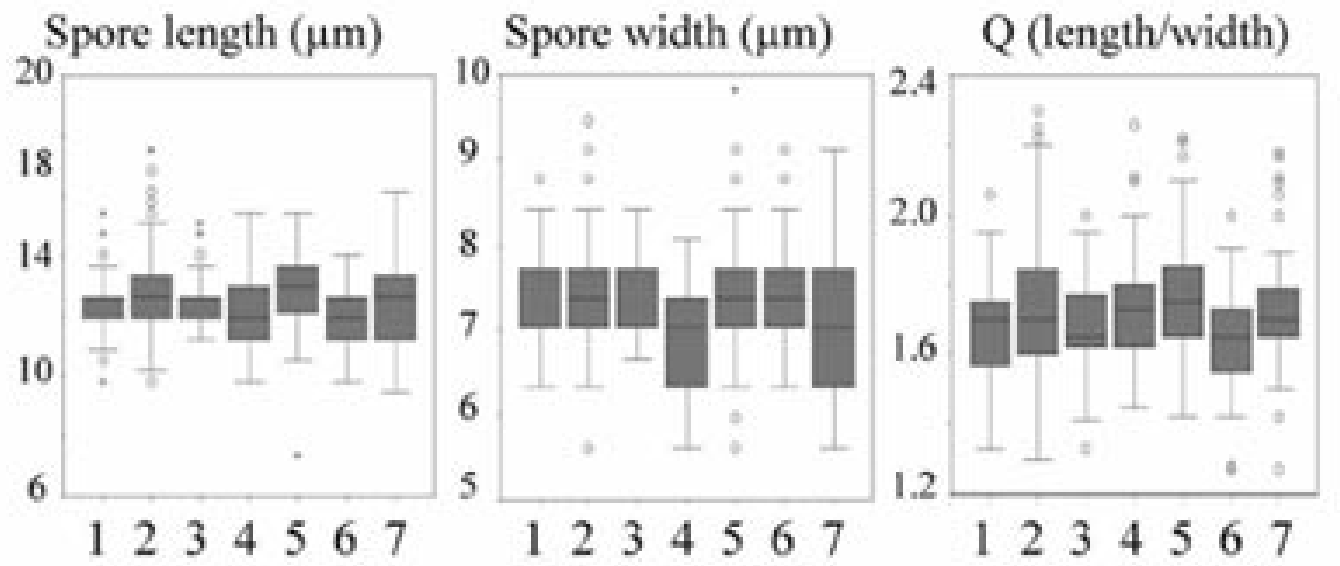

Fig. 2. Box plots for spore length, width and Q of alpine taxa of Cortinarius subgenus Myxacium, section Myxacium only: C. absarokensis (number of collections studied/number of spores measured $=3 / 155)$ as well as different forms and varieties of C. alpinus $(=C$. favrei) are considered (C. favrei (16/469), C.f.fm. pallida (2/62), C.f. viol. lamellae (2/62), C. alpinus (5/155), C.f. var. microsporus (3/93), C. favrei var. ? (3/93). Boxes represent the median, the upper and lower quartiles, and the extreme values; outliners are shown as dots.

Parsimony analysis with gaps treated as missing data yielded 10000 MPT (tree score $=142$ steps, $\mathrm{CI}=0.9155, \mathrm{CI}$ excluding uninformative characters $=0.8681, \mathrm{RI}=0.9544, \mathrm{RC}=0.8737)$. A strict consensus tree is shown in Fig. 4.

The best fitting ML model selected by Modeltest was the HKY85+G model with gamma distributed site-to-site rate variation. The estimated transition/transversion ratio was 1.6239, the gamma-shape parameter 1.1392 , the base frequencies were $\mathrm{A}=0.25840 \mathrm{C}=0.20110 \mathrm{G}=0.20310 \mathrm{~T}=0.33740$, and the proportion of invariable sites was zero. The heuristic ML search was aborted after 31 hours, it resulted in $230 \mathrm{ML}$ trees with a $-\mathrm{Ln}$ likelihood $=1613.32$. ML trees did not significantly differ from each other or from MP trees, one randomly chosen ML phylogram is shown in Fig. 4.

Phylogenetic analyses of the included species of subgenus Myxacium showed a good discrimination between the taxa of the two sections Myxacium and Defibulati. However, resolution within the focal study group was comparatively low: both tree topologies revealed a subclade formed by C. mucosus, C. muscigenus and C. pingue. One collection of C. mucosus growing under Pinus sibirica in the Altai (Russia) is sister to this clade in the ML phylogeny. C. fennoscandicus and C. septentrionalis formed clades within the focal study group, but constancy of these clades was uncertain due to the low number of included sequences. No resolution could be obtained on species or variety level for C. alpinus, C. absarokensis, or C. trivialis. Tree topologies indicate a possible lineage of $C$. trivialis collections from Russia, Italy, Spain and the Ukraine.

As shown in Fig. 4, phylograms had very short branches: base differences between included ITS sequences are generally very low in this group. Pair wise base differences as calculated in PAUP* varied between $0-0.7 \%$ within pairs of ingroup taxa, up to $1 \%$ between ingroup taxa and outgroup taxa. 

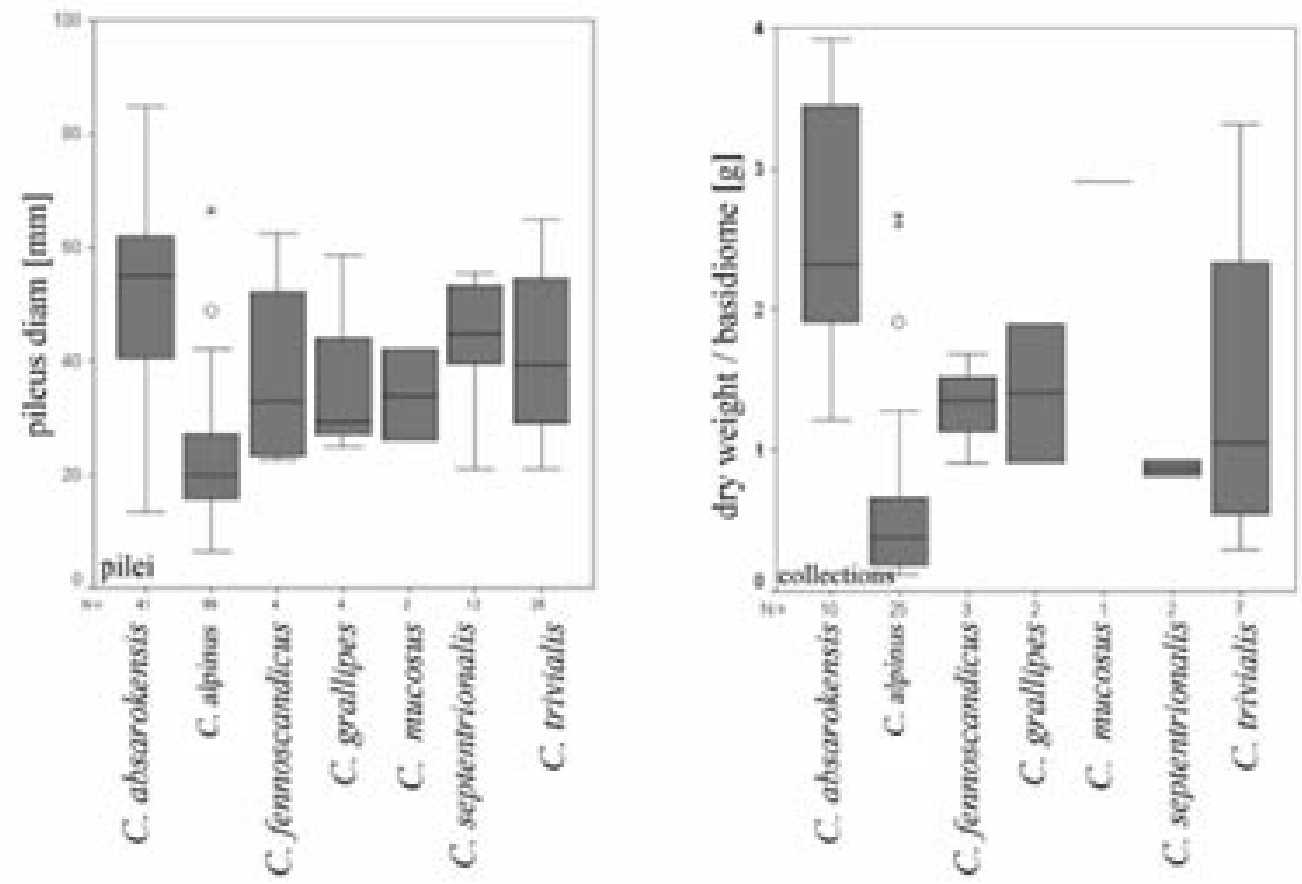

Fig. 3. Box plots for pileus diameter and average dry weight of mature (= open) basidiomes of taxa belonging to section Myxacium. Boxes represent the median, the upper and lower quartiles, and the extreme values; outliners are shown as dots. $\mathrm{n}=$ number of pilei / collections measured for each species.

\section{DISCUSSION}

\section{Morphometric analyses}

Spore size, shape, and ornamentation are usually quite uniform in species of the study group, as already shown by Bendiksen et al. (1993). However, a few characters are constant and can be regarded as good and distinctive for recognition of taxa. Thus, the spore size and shape is distinctive for two species in this complex: C. mucosus, with narrowly amygdaliform spores with a spore quotient $>$ 1.8, and C. muscigenus, with large amygdaliform spores (Bendiksen et al. (1993) measure 13-16 $\times 7.5-9.5 \mu \mathrm{m})$ and a spore quotient $<1.8$. All other taxa of this complex have amygdaliform to elliptical or sublimoniform spores. Spore shape in C. alpinus tends more towards being elliptical, in C. absarokensis spores appear slightly amygdaliform due to a more conical apex. However, species delimitation is difficult based on spore characters. Other distinctive micro-morphological characters (like pileipellis structures, cystidia) are not known for this group of fungi.

Basidiome size and biomass can be distinctive characters, especially for species with overlapping habitat such as C. absarokensis and C. alpinus. However, they are not distinctive between the other species involved. C. absarokensis and C. alpinus have both been collected in the same areas in Austria (Obergurgl) or in Norway (Finse) at about $2000 \mathrm{~m}$. They co-occur, as their respective 


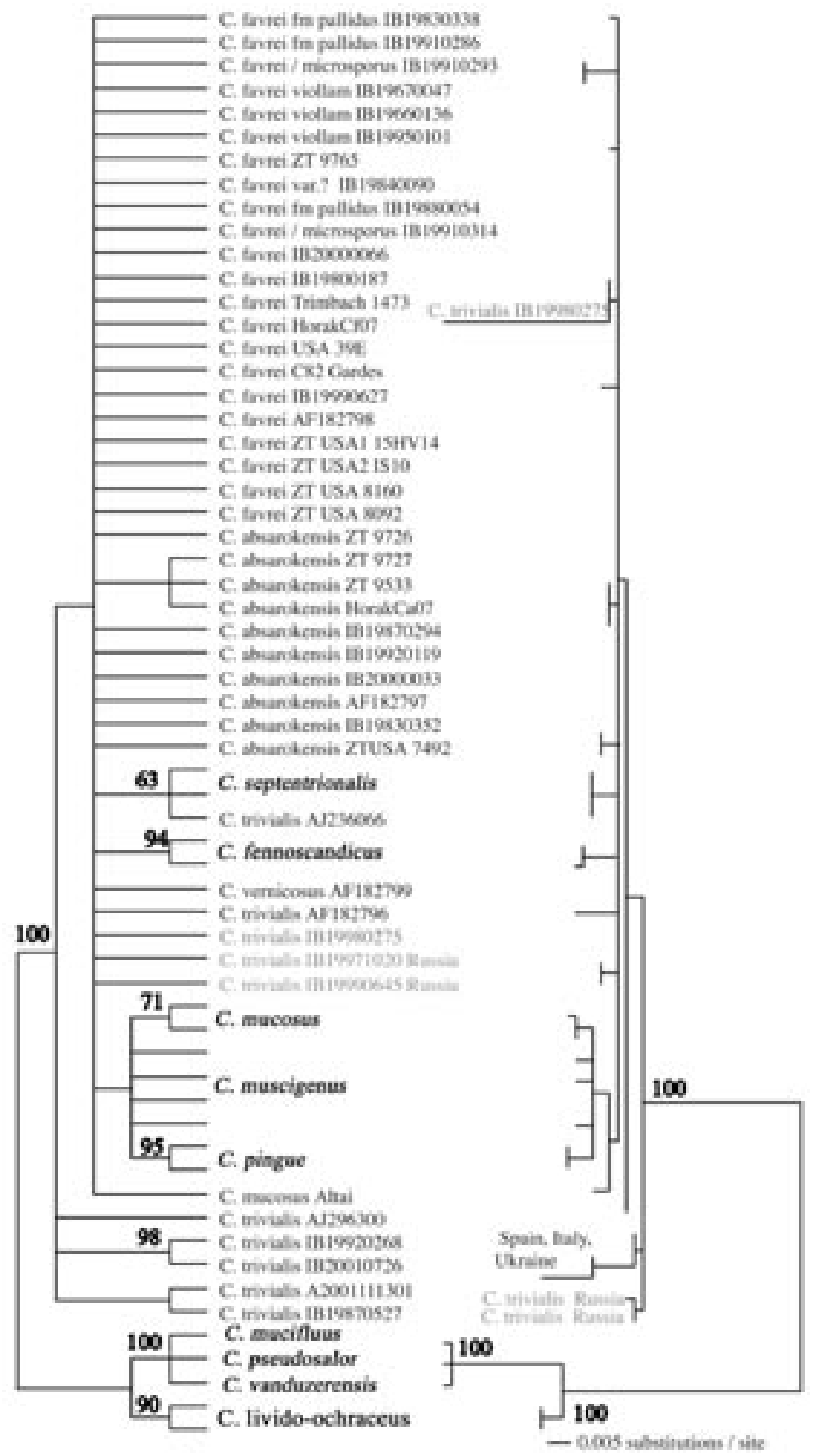

Fig. 4. Maximum parsimony strict consensus tree resulting from 10000 MPT with a tree length of 142 steps (left) and one of 210 ML trees with a ln of 1613.32 (right) resulting from the phylogenetic analyses of 56 rDNA ITS sequences from 10 species belonging to Cortinarius subgenus Myxacium section Myxacium. Four species of section Defibulati were used as outgroup. Bootstrap values > $69 \%$ are shown above branches. Taxa changing their position in the MP and ML tree are shown in grey colour. 
phytobionts do, in the same area. This observation contradicts the hypothesis, that size and biomass are analogous characters, which vary due to adaptations to extreme environments such as the alpine zone. In these two special cases, variation of basidiome size could only be regarded as adoption to a special phytobiont.

\section{Phylogenetic analyses}

The rDNA ITS region has been widely applied to resolve phylogenies on species and subgenus level, and is therefore a useful tool for the molecular identification of fungi from environmental samples. However, while in many fungal groups rDNA ITS sequences are very useful for addressing questions on species level, they can be either too variable (nearly impossible to align) in certain groups of fungi, e.g. in Xerocomus (Peintner et al. 2003) and Inocybe (Matheny 2005), or too conserved in other groups, e.g. in Hebeloma (Aanen et al. 2000), in Gymnopilus (Moser et al. 2001) or in Alnicola (Moreau et al. 2006) for addressing species level issues.

\section{Species concepts in fungi}

Species concepts and criteria to recognize species are much discussed and controversial topics (e.g. Ciferri, 1932, Clemençon 1977, Bresinsky et al. 1976, Goldstein \& DeSalle 2000, Høiland 1986, Lamoure 1989, Miller \& Methven 2000, Petersen \& Hughes 1999). Fungal species have usually been defined by (i) phenotypic characterization (morphological species), (ii) reproductive isolation (biological species), or (iii) by genetically differentiated clades (phylogenetic species) (Baum 1992, Baum et al. 1995, Taylor et al. 2000). However, different methods of species recognition may have different empirical consequences, as has been shown in several groups of fungi (Vilgalys \& Sun 1994, Hibbett et al. 1995, Aanen et al. 2000, Harrington et al. 2002, Miller \& Huhndorf 2004, Rehner \& Buckley 2005, Moreau et al. 2006).

Morphological species recognition (MSR) is the dominant method of species recognition, as it is a basic element of the description of every species, and can be applied to most groups of fungi. Biological species recognition (BSR) using mating tests has been widely used to delimit reproductively isolated biological species sensu Mayr (1942). However, the relationship of in vitro mating behaviour and the interbreeding potential in nature remains unclear. Moreover, many fungal species cannot be cultured as monokaryons, and for approximately $20 \%$ of the fungal kingdom sexual activity has not been observed (Hawksworth et al. 1995). Phylogenetic species recognition (PSR) can be applied to all fungi, even to those, which are asexual or uncultivable, and is now challenging MSR and BSR, especially in medically or economically important fungi (Cruse et al. 2002, O'Donnell et al. 2004).

A thorough comparison of PSR and BSR was carried out by Dettmenn et al. (2003) for the ascomycete model organism Neurospora crassa. They found that significant phylogenetic divergence precedes the development of reproductive isolation. This suggests that PSR using genealogical concordance can be used to reliably recognize species in fungal groups that are not candidates for BSR.

\section{Monophyletic groups and species concepts in Cortinariaceae}

Many ectomycorrhizal fungal species of Cortinariaceae are not candidates for BSR, as spore germination (and thus monokaryons for mating tests) is nearly impossible to obtain.

Species recognition must to be therefore based on morphology and phylogeny. Phylogenetic 
studies have been carried out for most genera (based on Singer 1986) recognized in Cortinariaceae. However, evidence becomes stronger and stronger that Cortinariaceae in Singers sense is not a monophyletic group (Moncalvo et al. 2002), and that e.g. the genus Inocybe (Matheny 2005) should constitute its own family Inocybaceae, which is sister to Crepidotaceae (Aime et al. 2005). Galerina is a polyphyletic genus, its lineages as well as the monophyletic genus Gymnopilus belong to Strophariaceae (Gulden et al. 2005). Multiple gene phylogenies will certainly contribute to a new and more natural approach of suprageneric classification in brown-spored mushrooms in the euagaric clade (James et al. 2006).

Genetic distance as a criterion for delimitation of species is mostly used within the framework of Mayr's biological species concept and is not free of assumptions about the nature of species or of speciation. However, PSR is still very difficult in Cortinarius and many other genera of fungi, especially because it is impossible to apply the same, objective (measurable) criteria for different groups of fungi. For example, rDNA ITS sequence variation is generally very low among morphologically distinct species of Cortinarius (Høiland \& Holst-Jensen 2000, Peintner et al. 2004, Frøslev et al. 2005), Hebeloma (Aanen et al. 2000), Gymnopilus (Moser et al. 2001) and Alnicola (Moreau et al. 2006), while it is comparatively high in species of Amanita (Zhang et al. 2004), Inocybe (Matheny 2005) or Galerina (Gulden et al. 2005).

In these genera with low divergence in the widely used rDNA ITS region, PSR are very difficult to apply. Within Hebeloma, BSR can also be applied to test species concepts. In his extensive investigations (Aanen \& Kuyper 1999, Aanen et al. 2001), Aanen found that no generalisations are possible about the relation of speciation (the formation of distinct BS) and nuclear ITS divergence. Such a relation was based on three main assumptions: (i) reproductive isolation is based on the slow accumulation of many genetic differences throughout the genome; (ii) genetic divergence automatically leads to reproductive isolation between species; and (iii) pre-mating and post-mating reproductive isolation have a similar genetic basis. However, so many exceptions have been demonstrated to these assumptions that they cannot be used with any reliability to distinguish different species. Therefore, the use of genetic distance to infer separate species (or the lack of these) is not parsimonious, its theoretical foundations are not well understood, and it cannot be applied over a wide range of plants, animals or fungi (Aanen et al. 2001, Ferguson 2002).

So what criteria and strategies can be applied for species recognition in Cortinarius and other fungi with low rDNA ITS sequence divergence? For a meaningful application of PSR, genealogical concordance should be implemented using variable regions of alternative genes, for example rpb1 and rpb2 (Matheny 2005), which already showed promising result in Cortinarius subgenus Phlegmacium (Frøslev et al. 2005).

Molecular tools help to interpret morphological and ecological characters in Basidiomycetes, and to assess their taxonomic value (homology). In the genus Alnicola, for example, it led to a reevaluation of the anatomical (cystidia, pileipellis) and ecological (host-specificity) characters that these groups where initially based on (Moreau et al. 2006). In Cortinarius subgenus Myxacium we now know that e.g. the presence of clamp connections is a good synapomorphic character for species of section Defibulati. Within section Myxacium, basidiome colours, spore shape and size, and characteristic veil remnants are the currently applied delimiting morphological characters. Moreover, the ecology is very important for species delimitation in this group. For now, these MSR cannot be verified with other methods. Geographical or niche differentiation has often been regarded and recognized as a driving force of speciation. The low divergence in rDNA ITS sequences suggests, that Cortinarius is a group of fungi where speciation is still going on. However, host specificity is a strong ecological driving force for phylogenetic divergence and reproductive isolation. Based on these arguments, we chose to recognize all eight morphologically and ecologically distinct units as Cortinarius species within the lineage Cortinarius subgenus Myxacium. 


\section{TAXONOMIC NOTES AND DESCRIPTIONS}

\section{Cortinarius favrei is a synonym of C. alpinus}

Cortinarius alpinus was described by Boudier with basidiospores 16-20 x 7-9 $\mu \mathrm{m}$ (Boudier 1895, van Brummelen 1969). Favre (1955) named his corresponding Cortinarius collections from the alpine zone $C$. alpinus Boud., but explicitly stated that the spores of his collections were remarkable smaller than cited by Boudier, reaching 11-14 × 6.5-8.5 $\mu \mathrm{m}$. Therefore, Moser (1955) described C. alpinus Boud. sensu Favre as C. favrei Moser. This was a nomen nudum and therefore validated by Henderson (Henderson 1958). Since then, C. alpinus Boud. and C. favrei Moser ex Henderson have been regarded as two distinct taxa mainly differing in spore size. According to Trimbach (1978) and Moser (1983), C. alpinus is macroscopically very similar to C. favrei, but has distinctly larger spores 16-20 $(22) \times 7-9 \mu \mathrm{m}$, and is very rare. However, no material is available in various herbaria, including IB and Trimbachs personal herbarium. Despite our extensive efforts, including correspondence with most European and American mycologists working with arctic-alpine fungi, no material of C. alpinus (with large spores) seems to exist.

Moreover, Boudier's spore measurements are controversial, but van Brummelen (1969) published a method to establish the spore size of Boudier's publications: from 1885 on Boudier's values for microscopic sizes in the descriptions were exaggerated. His measurements were usually about one-tenth too high (Boudier 1895, van Brummelen 1969). Using van Brummelen's scale designed to measure spores from Boudier's drawings we measured the four spores depicted in Boudier's original description (Fig. 5). Without apiculus they are 14-18 $\times 6-8 \mu \mathrm{m}$ (single values: $18 \times 8 \mu \mathrm{m}, 17 \times 8 \mu \mathrm{m}$, $16 \times 7 \mu \mathrm{m}$ and $14 \times 6 \mu \mathrm{m}$ ). The range (min-max) of the 992 measured spores (32 collections) of $C$. favrei is $9.6-17.5 \times 5.6-9.7 \mu \mathrm{m}$, mean $\pm \mathrm{sd}=12.6 \pm 1.2 \times 7.4 \pm 0.7 \mu \mathrm{m}$. Extreme, partly abnormal looking spores reaching a length of $20 \mu \mathrm{m}$ were also observed (e.g. IB19950101). Also Bendiksen et al. (1993) observed a high heterogeneity when measuring spores from the lamellae, which in the latter case can reach up to $18 \mu \mathrm{m}$ spore length. Variation in spore size within C. alpinus collections is high: some of our collections had consistently larger (e.g. ZT8160: 13.3-17.4 × 6.3 $-8.7 \mu \mathrm{m}$ ) or smaller spores (e.g. IB19840181: 9.8-13.3 × 6.3-8.8 $\mu \mathrm{m}$ ). However, when considering all collections, transitions between these extreme values exist, and it is impossible to clearly distinguish small-spored and large-spored collections.

Because of the minimal differences between Boudier's corrected spore measurements and our data, we can no longer keep C. alpinus and $C$. favrei as two distinct taxa. As a consequence, the older epithet $C$. alpinus Boud. has to be considered as the valid name for $C$. favrei. A recombination or validation of proposed varieties or forms is not recommended.

No constant differences could be observed for the varieties and/or forms of $C$. alpinus: thus, this taxon shows considerable variation in the pileus colour, the lamellae can be violaceous when young, and the spore size can vary considerably between different collections.

Cortinarius alpinus and C. absarokensis: Description of two species of arctic and alpine environments

Cortinarius alpinus Boud. 1895

Bulletin de la Societe' Mycologique du France 11:27, Table 11. Synonyms: 


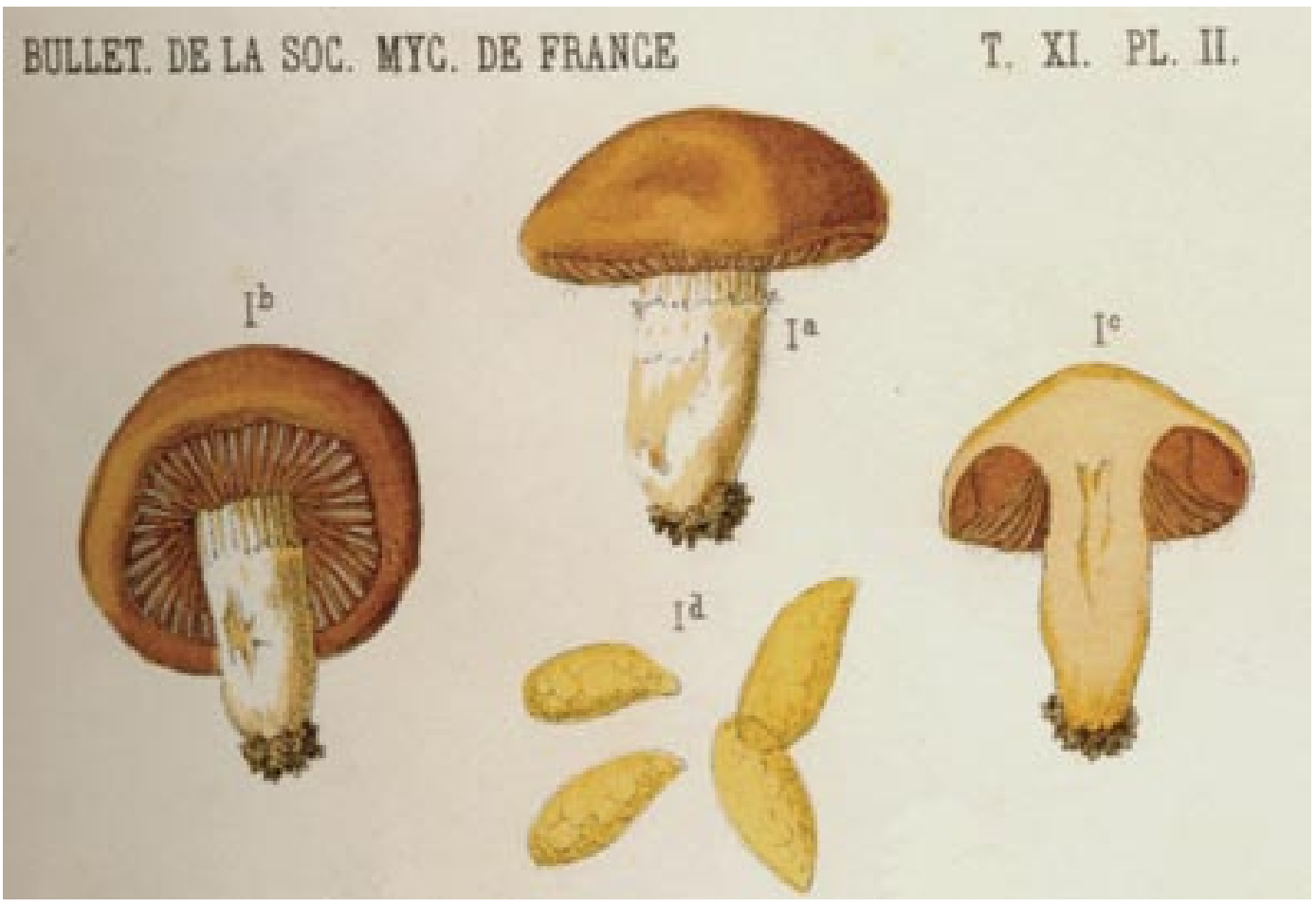

Fig. 5. Drawing of Cortinarius alpinus made by Boudier.

Cortinarius favrei M.M. Moser ex Henderson 1958, Notes Roy. Bot. Gard. Edinburgh 22: 593 595. Cortinarius favrei forma pallidus M.M. Moser et McKnight 1987, Arctic and Alpine Mycology, II (New York): 301.

Typus material of C. alpinus: not available.

C. alpinus is the only species of Myxacium section Myxacium occurring in arctic and alpine areas in association with dwarf willows (S. retusa, S. reticulata, S. herbacea, S. polaris, S. rotundifolia, Dryas spp.). Representatives of this taxon have an alpine and a circumpolar distribution (Austria, Canada, France, Italy, Norway, Scotland, Sweden, Switzerland, Spitzbergen, Siberia, USA including Alaska, Greenland), and are very common in suitable areas. The pileus diameter varies from 1.5-5 $(-7) \mathrm{cm}$. The range of spore size (values rounded to $0.5 \mu \mathrm{m}$ ) is $9.5-17.5 \times 5.5-9.5 \mu \mathrm{m}$, mean $\pm \mathrm{sd}=$ $12.5 \pm 1.0 \times 7.5 \pm 0.5 \mu \mathrm{m}$. Spore size variation is high due to the occurrence of basidia with 2 and 4 sterigmata; also abnormal spores sometimes occur, especially on the lamellae.

Cortinarius favrei forma pallidus was delimited from typical C. favrei by its fairly pale ochraceous, then pallid brown, pale orange brown pileus colours. A second form, Cortinarius favrei forma "with violaceous lamellae" was never validly published, but mentioned by Moser (2001). However, these two forms are probably only strain specific differences in pigment concentrations. As typical for C. alpinus, also spore size varies considerably within collections assigned to these "forms" (Tab. 2).

Also C. favrei var. microsporus was never validly published: Moser (2001) mentioned this potential variety with basidiospores being $8-12 \mu \mathrm{m}$ long. When applying the concept of an average 
spore length $<12.5 \mu \mathrm{m}$, the following collections should be assigned to this variety: IB19590013, IB19670047a, IB19840181b, IB19910293, IB19920151, IB19950027, IB19950102, IB20000066, Pacioni 27.07.01/klein, Pacioni 27.07.01/groß, Trimbach 2216, Trimbach 1473, ZT9765. However, all these taxa lay within the range of variability of basidiospores of $C$. alpinus. A distinction of taxa based on such a variable character is not warranted.

\section{Cortinarius absarokensis M.M. Moser \& McKnight}

Arctic and Alpine Mycology II: (New York): 302 (1987)

Holotypus IB19830352

This species was delimited from $C$. favrei by its more robust habit, the larger basidiomes and the habitat with Salix bushes, which are from 20-200 cm high (S. planifolia, S. arctica, S. foetida, S. phylicifolia). The fresh pileus diameter is given as (3-) 5-11 (-13) cm (Moser \& McKnight, 1987). Spores from the type material are elongate almond-shaped, (12.1) $13.6 \pm 0.9(15.4) \times(7.2) 7.7 \pm 0.4$ (8.8) $\mu \mathrm{m}, \mathrm{Q}=1.8$. Cortinarius absarokensis has mean spore values ( 8 collections, values rounded to $0.5 \mu \mathrm{m})$ of $(10.0) 12.5 \pm 1.0(15.5) \times(6.5) 7.5 \pm 0.5(9.0) \mu \mathrm{m}, \mathrm{Q}=(1.3) 1.7 \pm 0.1$ (2.1). Values vary little between collections from U.S.A, Austria, France, Norway (data not shown) and Greenland.

\section{ACKNOWLEDGEMENTS}

I express my gratitude to all friends and colleagues providing fungal specimen for analysis; I especially thank Monique Gardes, Egon Horak, Giovanni Pacioni, and Jaques Trimbach. Thanks to Sabine Vallant for help with spore measurements. This study was supported by the Leopold-Franzens-University Innsbruck (Förderungen der LFU Innsbruck 2002).

\section{REFERENCES}

Aanen, D.K. \& Kuyper, T.W. 1999. Intercompatibility tests in the Hebeloma crustuliniforme complex in northwestern Europe. - Mycologia 91: 783-795.

Aanen, D.K., Kuyper, T.W., Boekhout, T. \& Hoekstra, R.F. 2000. Phylogenetic relationships in the genus Hebeloma based on ITS1 and 2 sequences, with special emphasis on the Hebeloma crustuliniforme complex. - Mycologia 92: 269-281.

Aime, M.C., Vilgalys, R. \& Miller, O.K. 2005. The Crepidotaceae (Basidiomycota, Agaricales): Phylogeny and taxonomy of the genera and revision of the family based on molecular evidence. - Am. J. Bot. 92: 74-82.

Baum, D. 1992. Phylogenetic species concepts. - Tree 7: 1-2.

Baum, D. \& Donoghue, M.J. 1995. Choosing among alternative "phylogenetic" species concepts. - Syst. Bot. 20: 560-573.

Bendiksen, E., Bendiksen, K. \& Brandrud, T.E. 1993. Cortinarius subgenus Myxacium section Colliniti (Agaricales) in Fennoscandia, with special emphasis on the arctic-alpine zones. - Sommerfeltia 19: 1-37.

Boudier, E. 1895. Description de quelques nouvelles especes de champignons recoltees dans les regions elevees des Alpes du Valais, en aout 1894. - Bull. Soc. mycol. Fr. 11: 27-30. 
Bresinsky, A., Hilber, D. \& Molitoris, H.P. 1976. The genus Pleurotus as an aid for understanding the concept of species in basidiomycetes. - In: Clemençon, H, (eds), Species concept in Hymenomycetes, Cramer, Vaduz, pp 229-258.

van Brummelen, J. 1969. Clues for the determination of the spore-sizes in Boudier's illustrated publications. - Persoonia 5: 233-236.

Ciferri, R. 1932. The criteria for delimitation of species in mycology. - Ann. Myc. 30: 122-136.

Clémençon, H. (ed.) 1977. The species concept in Hymenomycetes. - Cramer, Vaduz.

Cruse, M., Telerant, R., Gallagher, T., Lee, T. \& Taylor, J.W. 2002. Cryptic species in Stachybotrys chartarum. - Mycologia 94: 814-822.

Dettman, J.R., Jacobson, D.J., Turner, E., Pringle, A. \& Taylor, J.W. 2003. Reproductive isolation and phylogenetic divergence in Neurospora: Comparing methods of species recognition in a model eukaryote. - Evolution 57: 2721-2741.

Favre, J. 1955. Les champignons supérieurs de la zone alpine du Parc National Suisse. - Ergebn. wiss. Unters. schweiz. Nat. Parks 5: 1-212.

Ferguson, J.W.H. 2002. On the use of genetic divergence for identifying species. - Biol. J. Linn. Soc. 75: 509-516.

Frøslev, T.G., Matheny, P.B. \& Hibbett, D.S. 2005. Lower level relationships in the mushroom genus Cortinarius (Basidiomycota, Agaricales): A comparison of RPB1, RPB2, and ITS phylogenies. - Molec. Phyl. Evol. 37: 602-618.

Goldstein, P.Z. \& DeSalle, R. 2000. Phylogenetic species, nested hierarchies, and character fixation. - Cladistics 16: 364-384.

Gulden, G., Stensrud, O., Shalchian-Tabrizi, K. \& Kauserud, H. 2005. Galerina Earle: A polyphyletic genus in the consortium of dark-spored agarics. - Mycologia 97: 823-837.

Gulden, G., \& Lange, M. 1971. Studies in the Macromycete flora of Jotunheimen, the Central Mountain Massif of south Norway. - Norw. J. Bot. 18: 1-46.

Harrington, T.C. \& Rizzo, D.M. 1999. Defining Species in the Fungi. - In: Worrall, J, (ed), Structure and dynamics of fungal populations, Kluwer, New York, pp. 43-70.

Harrington, F.A., Pashenova, N.V., McNew, D.L., Steimel, J. \& Yu., K.M. 2002. Species delimitation and host specialization of Ceratocystis laricicola and C. polonica to larch and spruce. - Pl. Dis. 86: 418-422.

Hawksworth, D.L., Kirk, P.M., Sutton, B.C. \& Pegler, D.N. 1995. Ainsworth \& Bisby's dictionary of the Fungi. - International Mycological Institute, Cambridge.

Henderson, D.M. 1958. New and interesting Scottish fungi: I. - Not. r. bot. Gdn Edinb. 22: 593595.

Hibbett, D.S., Fukumasa Nakai, Y., Tsuneda, A. \& Donoghue, M.J. 1995. Phylogenetic diversity in shiitake inferred from nuclear ribosomal DNA sequences. - Mycologia 87: 618-638.

Høiland, K. 1986. The species concept in agarics. - Blyttia 44: 64-75.

Høiland, K. \& Holst-Jensen, A. 2000. Cortinarius phylogeny and possible taxonomic implications of ITS rDNA sequences. - Mycologia 92: 694-710.

James, T.Y., Kauff, F., Schoch C.L. et al. [70 more co-authors] 2006. Reconstructing the early evolution of Fungi using a six-gene phylogeny. - Nature 443: 818-822.

Jamoni, P.G. \& Bon, M. 1993. Note di micologia alpina: Reperti rari e nuovi della zona alpiona del Massiccio del Monte Rosa e Dintorni. - Rivista di Micologia 36: 3-20.

Kühner, R. \& Lamoure, D. 1986. Catalogue des Agaricales (Basidiomycetes) de la zone alpine du Parc National de la Vanoise et des regions limitrophes. - Trav. sci. Parc natl Vanoise 15: 103-187.

Matheny, P.B. 2005. Improving phylogenetic inference of mushrooms with RPB1 and RPB2 nucleotide sequences (Inocybe; Agaricales). - Molec. Phyl. Evol. 35: 1-20.

Mayr, E. 1942. Systematics and the Origin of Species. - Columbia University Press, New York. 
Miller, A.N. \& Huhndorf, S.M. 2004. Using phylogenetic species recognition to delimit species boundaries within Lasiosphaeria. - Mycologia 96: 1106-1127.

Miller, A.N. \& Methven, A.S. 2000. Biological species concepts in eastern North American populations of Lentinellus. - Mycologia 92: 792-800.

Moncalvo, J.M., Vilgalys, R., Redhead, S.A., Johnson, J.E., James, T.Y., Aime, M.C., Hofstetter, V., Verduin, S.J.W., Larsson, E., Baroni, T.J., Thorn, R.G., Jacobsson, S., Clemencon, H. \& Miller, O.K. 2002. One hundred and seventeen clades of euagarics. - Molec. Phyl. Evol. 23: 357-400.

Moreau, P.-A., Peintner, U. \& Gardes, M. 2006. Phylogeny of Alnicola (Cortinariaceae) based on rDNA sequences with special emphasis on host specificity and evolution of morphological characters. - Molec. Phyl. Evol. 38: 794-807.

Moser, M. 1955. Blätter- und Bauchpilze. 2. Aufl. - Fischer, Stuttgart.

Moser, M. 1983. Die Röhrlinge und Blätterpilze. 5. Aufl. - In: Gams, W. (ed.). Kleine Kryptogamenflora. Bd. IIb/2, Fischer, Stuttgart, pp. 1-533.

Moser, M. 1993. Studies on North American Cortinarii. III. The Cortinarius flora of dwarf and shrubby Salix associations in the alpine zone of the Windriver Mountains, Wyoming, USA. - Sydowia 45: 275-306.

Moser, M. 2001. Rare, debated and new taxa of the genus Cortinarius (Agaricales). - Libreria Mykoflora, Alassio.

Moser, M. \& McKnight, K. 1987. Fungi (Agaricales, Russulales) from the alpine zone of the Yellowstone National Park and the Beartooth Mountains with special emphasis on Cortinarius. - Arct. alp. Mycol. 2: 299-317.

Moser, M., Ladurner, H., Peintner, U. \& Kirchmair, M. 2001. Gymnopilus turficola (Agaricales), a new species from sub- arctic palsa mires and its phylogentic relationship based on ITS sequences. - Nord. J. Bot. 21: 321-327.

Nezdoiminogo, E.L. 1983. Shlyapotschniye gribi SSSR. Rod Cortinarius Fr. - NAUKA, Leningrad.

Nezdoiminogo, E.L. 2002. Agaricoid macromycetes of the archipelagoes of Franz-Josef Land and Severnaya Zemlya. - Mikol. Fitop. 36: 35-42.

O’Donnell, K., Sutton, D.A., Rinaldi, M.G., Magnon, K.C., Cox, P.A., Revankar, S.G., Sanche, S., Geiser, D.M., Juba, J.H., van Burik, J.A.H., Padhye, A., Anaissie, E.J., Francesconi, A., Walsh, T.J. \& Robinson, J.S. 2004. Genetic diversity of human pathogenic members of the Fusarium oxysporum complex inferred from multilocus DNA sequence data and amplified fragment length polymorphism analyses: Evidence for the recent dispersion of a geographically widespread clonal lineage and nosocomial origin. - J. clin. Microbiol. 42: 5109-5120.

Peintner, U., Kirchmair, M., Moser, M., Pöder, R. \& Ladurner, H. 1999. Ergebnisse der 26. Mykologischen Dreiländertragung in Rotholz-Jenbach (Tirol) von 29. August bis 5. September 1998. - Österr. Z. Pilzk. 8: 83-123.

Peintner, U., Moser, M. \& Vilgalys, R. 2002. Rozites, Cuphocybe and Rapacea are taxonomic synonyms of Cortinarius: new names and new combinations. - Mycotaxon: 447-452.

Peintner, U., Ladurner, H. \& Simonini, G. 2003. Xerocomus cisalpinus sp. nov., and the delimitation of species in the Xerocomus chrysenteron complex based on morphology and rDNA-LSU sequences. - Mycol. Res. 107: 659-679.

Peintner, U., Moncalvo, J.-M. \& Vilgalys, R. 2004. Toward a better understanding of the infrageneric relationships in Cortinarius (Agaricales, Basidiomycota). - Mycologia 96: 1042-1058.

Petersen, R.H. \& Hughes, K.W. 1999. Species and speciation in Mushrooms. - Bioscience 49: 440451.

Posada, D. \& Crandall, K.A. 1998. Modeltest: testing the model of DNA substitution. - Bioinfor- 
matics 14: 817-818.

Quinn, G.P. \& Keough, M.J. 2002. Experimental design and data analysis for biologists. - Cambridge University Press, U.K.

Rehner, S.A. \& Buckley, E. 2005. A Beauveria phylogeny inferred from nuclear ITS and EF1-alpha sequences: evidence for cryptic diversification and links to Cordyceps teleomorphs. - Mycologia 97: 84-98.

Schmid-Heckel, H. 1985. Zur Kenntnis der Pilze in den nördlichen Kalkalpen. Mykologische Untersuchungen im Nationalpark Berchtesgaden. - Natl. Park Berchtesgaden Forsch. Ber. 8: 1-201.

Senn-Irlet, B.I. 1987. Ökologie, Soziologie und Taxonomie alpiner Makromyzeten (Agaricales, Basidiomycetes) der Schweizer Zentralalpen. - PhD Thesis, Univ. Bern, Bern.

Singer, R. 1986. The Agaricales in modern taxonomy, ed. 4. - Koeltz, Könistein.

Swofford, D.L. 2003. PAUP*. Phylogenetic Analysis Using Parsimony (*and Other Methods). Version 4. - Sinauer, Sunderland, MASS.

Taylor, J.W., Jacobson, D.J., Kroken, S., Kasuga, T., Geiser, D.M., Hibbett, D.S. \& Fisher, M.C. 2000. Phylogenetic species recognition and species concepts in fungi. - Fung. Genet. Biol. 31: 21-32.

Thomas, K.A., Peintner, U., Moser, M. \& Manimohan, P. 2002. Anamika, a new mycorrhizal genus of Cortinariaceae from India and its phylogenetic position based on ITS and LSU sequences. - Mycol. Res. 108: 245-251.

Trimbach, J. 1978. Materiel pour une "check-list" des Alpes maritimes (suite). - Docum. mycol. 8: 39-53.

Vilgalys, R. \& Sun, B.L. 1994. Ancient and recent patterns of geographic speciation in the oyster mushroom Pleurotus revealed by phylogenetic analysis of ribosomal DNA sequences. - Proc. natl Acad. Sci. 91: 4599-603.

Watling, R. 1977. Larger fungi from Greenland. - Astarte 10: 61-71.

Watling, R. 1987. Larger Arctic-Alpine fungi in Scotland. - Arct. alp. Mycol. 2: 17-45.

Zhang, L.F., Yang, J.B. \& Yang, Z.L. 2004. Molecular phylogeny of eastern Asian species of Amanita (Agaricales, Basidiomycota): taxonomic and biogeographic implications. - Fung. Div. 17: 219-238. 